\title{
ВЫШИВКА ТРАДИЦИОННОЙ ОДЕЖДЫ ВОРОНЕЖСКИХ ПЕРЕСЕЛЕНЦЕВ АЛТАЙСКОГО КРАЯ КАК ОТРАЖЕНИЕ КУЛЬТУРНОЙ САМОБЫТНОСТИ ЭТНИЧЕСКОЙ ГРУППЫ
}

\author{
Т.Ю. Ларина \\ Алтайский государственный институт культуры, Барнаул, Россия, \\ e-mail: Tatyana.larina.15@mail.ru
}

Работа посвящена изучению вышивального искусства Алтайского края. Основной акцент делается на описание традиционной вышивки в одежде воронежских переселенцев - как части материального культурного наследия Алтайского региона, обладающей локальными особенностями. На основе экспедиционных исследований рассмотрены сохранившиеся элементы традиционной одежды, которые подчеркивают специфику данной группы населения: используемые материалы, технологии, колорит, композиция, орнамент.

Ключевые слова: духовная безопасность, культурное наследие, традиция, вышивка, Алтайский край, воронежские переселенцы, традиционный костюм.

\section{EMBROIDERY OF THE ALTAI REGIONAL VORONEZH SETTLER'S TRADITIONAL NATIVE DRESS AS A REFLECTION OF CULTURAL IDENTITY OF THE ETHNIC GROUP}

\author{
T.Yu. Larina \\ Altai State Institute of Culture, Barnaul, Russia, \\ e-mail: Tatyana.larina.15@mail.ru
}

The article focuses on the results of the study on the embroidery art of the Altai region. The main accent is made on description of traditional embroidery at in the costumes of the Voronezh settlers as a part of material cultural heritage of the Altai region, having some local features. Based on expeditionary researches, author considers remaining elements of traditional costumes, which stress the specifics of the given group of population the used materials, technologies, color, and ornament.

Keywords: spiritual security, cultural heritage, tradition, embroidery, the Altai region, the Voronezh settlers, traditional costume. 
Одной из задач культурной политики на современном этапе является обеспечение духовной безопасности нации, и прежде всего путем сохранения традиционных матриц национальной культуры. Проблема сохранения культурной самобытности первична в системе государственных приоритетов - от ее решения зависит успешность решения всех других проблем, в частности духовного здоровья нации.

Культурное наследие - это созданные человеком в прошлом материальные и духовные творения, обладающие культурной ценностью. Наследие питает современную науку, образование, культуру. Наравне с природными богатствами это главное основание для национального самоуважения и признания мировым сообществом.

В связи с процессами глобализации, стандартизации и урбанизации появляется острая необходимость в отстаивании самобытной культуры народов и отдельных групп, их самоидентификации, что усиливает тенденцию, направленную на сохранение их традиций, обычаев. Отдельный пласт культурного наследия составляют народные ремесла, рукоделие, в частности традиционная вышивка.

Традиционная вышивка сегодня не востребована с той функцией, которая существовала века и тысячелетия. А это значит, что вышитые предметы не соответствуют современному окружению человека. Вместе с тем в последнее время наметилась тенденция обращения людей к «русскому стилю», главным образом в профессиональной среде модельеров, дизайнеров интерьеров и т.п. Отсутствие этнографических знаний о технологиях, материалах декорирования вышивкой одежды, предметов быта, их этнической принадлежности, локальных особенностях приводит к стилизации, порой абсолютно не соответствующей действительности и демонстрирующей лишь поверхностный взгляд на традиционную культуру.

Именно поэтому изучение традиционных технологий ремесел, в том числе вышивки, сегодня является актуальным и своевременным. Особую роль в этом поступательном процессе играют музеи. Музеи Алтайского края, являясь «институтом социальной памяти», обладают уникальными коллекциями, документирующими технологии традиционной вышивки старожильческого и переселенческого населения Алтая начиная с XIX в.

Традиционная вышивка Алтайского края носит своеобразный характер. В первую очередь это связано со спецификой заселения русским населением, которое происходило несколькими этапами и осуществлялось с различных территорий европейской части России: первоначально преимущественно из северных губерний, а позже - из средней полосы и с юга. Каждая волна переселенцев имела свои традиции, знания и умения, но со временем шло взаимодействие различных этнических групп, проживающих на одной территории. Тем не менее каждая этническая группа русских имеет свои отличительные черты в вышивке, которые проявляются в технологиях, колорите, орнаменте, материалах.

Воронежские переселенцы относятся к позднепереселенческому населению. По мнению В.А. Липинской, переселенцы из Воронежской губернии активно переселялись уже с конца XIX в., наравне с крестьянами из Пермской, Вятской и Тамбовской губерний. Дело в том, что в 1891 г. страну охватил страшный неурожай. 
Спасаясь от голода, крестьяне двинулись в Сибирь.

Главным переселенческим районом стали западная степная и лесостепная части Алтайского округа. Воронежские крестьяне направлялись южнее - в Бийский округ и составили самый высокий процент этнического состава населения 81,2 процента. Росту переселенческого движения в начале XX в. способствовала Столыпинская аграрная реформа, направленная на развитие сильных хозяйств на местах. Вскоре поток крестьян перехлестнул южную границу Алтайского округа, начал распространяться в горы, в степной край (Липинская, 1996: 48-62).

Вышивка воронежских переселенцев, прибывших в конце XIX — начале XX в., самобытна и интересна для изучения и представлена, главным образом, в одежде. Традиционный костюм воронежцев можно разделить на два вида: комплекс одежды, привезенный переселенцами с мест исхода, и одежда, бытовавшая на территории Алтая.

Источников, характеризующих традиционную одежду, и вышивку в том числе, воронежских переселенцев на Алтае очень мало, но даже тот материал, который был обнаружен в ходе экспедиций, дает представление о воронежском костюме и людях, которые его носили. В ходе этнографических экспедиций 2016-2018 гг. были обнаружены следующие этнографические образцы одежды воронежских переселенцев: женская рубаха, понева - в Троицком районном краеведческом музее и передник - в Краеведческом музее г. Рубцовска. По словам сотрудницы Троицкого музея И.Г. Гросс, привезенную из Воронежской губернии одежду переселенцы, проживая на Алтае, почти не носили, а хранили в сундуках как семейную реликвию. Возможно, поэтому эта одежда сохранилась до наших дней.

В Троицкий краеведческий музей воронежский костюм передали дочери Александры Павловны Серкиной, 1908 г.р., рожденной в с. Веретеевском Готовской волости Воронежской губернии и переехавшей в 1961 г. в Троицкий район, с. Усть-Гавриловку.

Женская рубаха из этого комплекса - станушка — сшита длиной до пояса из домотканой холстины. Для рубахи использовали льняную ткань домашнего происхождения.

Основа - два полотнища со швами по бокам, собранные в сборке в верхней части, с прямыми поликами, пришитыми к стану и рукавам по основе, воротником-стойкой, длинным грудным разрезом, прямыми широкими рукавами и ластовицами под ними. Рукава сшиты из полутора полотнищ, собранных у запястья в сборки под обшивку. При сборке рубахи соединяются все стороны бельевым швом. В дальнейшем собирается горловина и рукава.

Рубаха декорирована вышивкой, расположенной на поликах и рукавах.

«Рубаха с черным узором» - так называют традиционную белую вышитую рубаху (и женскую, и мужскую) в селах Воронежской губернии. Ее главный отличительный признак - вышитые черные геометрические орнаменты на рукавах и плечевых вставках — «поликах». Вышивка представляет собой многоярусную композицию. В отличие, например, от украинской или западнорусской вышивки, в традиции воронежская вышивка симметрична относительно центра. 
Исследователь воронежского костюма Г.Я. Сысоева, классифицируя рубахи по композиции, выделяет пять типов (Сысоева, 2017а):

1) с ремнем или с узором. Рубахи с ремнем или с узором считаются самыми праздничными; они предназначены для особых случаев: свадьбы, двунадесятых или «годовых» праздников. Ремнем называют центральный узор, по обеим сторонам которого вверх (к горловине) и вниз (к запястью) располагаются подузорники. Завершается композиция сверху и снизу окончаниями - лапами.

На этих рубахах в основе центральных узоров - изображение различных ромбообразных фигур, основная из которых - репей (общерусское название), или арепой (местное название), в виде двойного и тройного косого креста. Ромб-репей в русской традиционной культуре символизирует идею плодовитости, обновления, а если он с лучиками, то одновременно является и солярным знаком, т.е. символом солнца. Знак солнца изображался на рубахах с золотым ремнем (т.е. с ремнем, вышитым золотыми нитями вприкреп);

2) рукава-полика. Композиция состоит из двух узоров без подузорников. Использовался в качестве праздничной вышивки;

3) с ферботами. На менее праздничных рубахах центральный узор заменяли ферботы - кружевные вставки, сплетенные на коклюшках. Они также изображали различные ромбические фигуры;

4) с ляховками. Рубаха с ляховками — разновидность рубахи с ферботами. Ляховками называли узкие вставки кружевных полос;

5)с кумачными поликами. Рубахи с кумачными (красными) поликами, имеющие невысокий статус праздничности.

Автор указывает и названия узоров: «репей, или арепой, — в форме ромба с лучами; во всю гребенку — ромб с множеством лучей, репей с крюками, разновидности: об четырех крюков, об восьми крюков, в том числе и с закручивающимися лучами, символизирующими движение солнца по небосводу; шлях — ковер из ромбических фигур; белокос - орнаментированный ромб с поперечной полосой; головастик - ромб с изрезанными вершинами. Подузорники, как правило, представляли собой часть основного узора: половина шляха, половина белокоса, половина головастика и т.д.» (Сысоева, 2017а).

Рубаха из фондов Троицкого музея, вероятно, относится ко второму типу рубаха «рукава-полика», декорированная вышитой композицией из двух узоров «половина головастика» и окончаниями «гребенка». По бокам полика и стану в месте их соединения по вертикали расположены подузорники «арепоюшек» и окончания «лапы».

Для вышивки использовали фабричные тонкие шерстяные нитки - шленку либо хлопчатобумажные нити (хотя они от стирки теряли цвет, приобретая серый или зеленый оттенок).

Техника исполнения вышивки - односторонняя или лицевая гладь, в Сибири, и в частности южном Алтае, данную технику называли «набор».

Шов «набор» - это двусторонняя вышивка, на изнанке узор получается обратный тому, который образуется на лицевой стороне. Чаще всего набором выпол- 
няют узор, состоящий из полос, клеток, ромбов и других мелких геометрических фигур. Набор - шов «вперед иголку» в несколько рядов. Расстояние между рядами - одна нить ткани. Игла при этом идет вдоль нити ткани, от одного конца узора до другого, переходя по счету нитей то на лицевую сторону, то на изнанку. Вышивка выполнялась слева направо по вертикали, снизу вверх (Куприянова, 2005).

Помимо набора в декорировании поликов и рукавов использованы такие виды швов, как «стебельчатый», «через край с петелькой» и «косичка». В украшении горловины и запястья - декоративный шов «роспись» и краевой шов «через край с петелькой». Здесь в отделке добавлен синий цвет нитей.

«Такие орнаменты, как на рукавах рубах, должны были быть и на завеске», пишет Г.Я. Сысоева. Завеска — короткий (от талии) фартук - обязательная деталь и женского, и девичьего костюма. Вышивка на завеске должна была соответствовать подузорникам и окончаниям надетой рубахи. Однако в настоящее время такой гармонии добиться уже не удается, поскольку одежда не воспроизводится, а передается по наследству, а завески быстрее всего изнашиваются» (Сысоева, 2017а).

В комплекс из фондов Троицкого музея завеска не входит. Но она была обнаружена в этнографической коллекции музея г. Рубцовска. Сведений об исполнителе, владельце в музее не содержится. Передник изготовлен из льняной ткани и состоит из двух полотнищ. Узор выполнен шерстяными нитями черного цвета. Вышивка со временем полиняла и приобрела зеленоватый цвет.

Передник-«завеска» сшился из двух коротких полотнищ конопляного холста; в верхней части они присобраны под узкую белую обшивку-тесьму с длинными петлями по краям. Близким по характеру узором отмечено место стыка полотнищ в нижней части передника. К подолу пришиты: золотистая лента фабричного производства (позумент) и полоски ткани фабричного производства болотного цвета и красного с мелким желтым узором.

В изготовлении передника-завески воронежских переселенцев используется такие виды декоративных швов и техник вышивки, как уголки, стебельчатый шов, роспись, набор, косичка. Применяются также элементы ткачества - зерна. В этнографическом образце вышивка выполняется шерстяными нитками черного цвета, тканый орнамент — красного цвета.

Орнамент, выполненный вертикальным набором, носит геометрический характер: кресты, квадраты, ромбы. Вышивкой в технике роспись изображены традиционные для воронежской губернии «мужички» (столбики) и «бабочки» (кустики).

Боковые края завески обшиты потайным швом белыми нитями. Два полотнища соединены между собой бельевым швом. Внизу по подолу в месте их соединения выполнена вышивка с использованием маскировочных швов, имеющих своей целью не только украсить изделие, но и закрыть соединительный шов. Здесь используются такие швы, как косичка, стебельчатый шов и роспись. Шов косичка выполнен нитями красного цвета.

Понева, как и рубаха, составляет основу воронежского комплекса. Понятие «понева» (понява) - общеславянское и обозначает кусок ткани, покрывало. Понева - это юбка, состоящая из трех полотнищ шерстяной или хлопчатобумажной 
ткани, стянутая на талии узким пояском - гашником. Из всех южнорусских губерний поневы Воронежской губернии по богатству и художественным качествам были самыми красочными нарядами.

Понева из фондов Троицкого краеведческого музея относится к типу глухой поневы (сшитой в виде юбки), изготовлена из домотканого полотна из овечьей шерсти, соткана в технике полотняного переплетения. Состоит понева из трех полотнищ шириной 46 см, вытканных в бело-красную клетку с цветными полосами, дополненными ручной вышивкой. Места соединения полотнищ декорированы сквозкой вышивкой ковровым настилом снизу доверху. Больше всего вышивки размещено на задней части. Переднее полотнище - прошва — является полотном без клетки такой же ширины, как и основные полотнища. На талии понева собрана в сборку и завязывается крученым шнурком (гашником).

Вышивка выполнена шерстяными нитями фабричного производства (шленкой). Техника вышивания - набор, в Воронежской губернии такие вышитые поневы называли в народе наборными (Сысоева, 2017б). Наборная вышивка ковровым настилом по подолу и полотнищам выполнена яркими, преимущественно красными нитями.

На полотнищах расположен вышитый орнамент «рябка» - неплотные ряды вышивки, сквозь которые видны просветы черной основы поневной ткани. Такой орнамент использовался для повседневных понев.

Г.Я. Сысоева пишет о том, что «по композиции коврового настила на полотнищах поневы сверху донизу вышивка в разных селах различается по так называемым пальчикам - поперечным вставкам темно-синего, зеленого, желтого цветов». В рассматриваемой поневе используется вышивка в один пальчик и выполнена поочередно синими и желтыми нитями» (Сысоева, 2017б).

Сквозки - место соединения двух полотнищ сзади - при декорировании образуют цветные вертикальные полосы, которые в воронежской губернии также назывались «пальчики» или «зубчики», по их числу определяется степень праздничности поневы: свозка в один пальчик (зубчик) или в два пальчика указывает на повседневную или расхожую поневу, в три-пять пальчиков - на различную степень праздничности. Сквозки на поневе Троицкого района состоят из трех пальчиков.

Обильно украшен вышивкой подол поневы, как главный признак обрядовой функции. На подшивке размещен орнамент «цветной столбик» в 40 нитей, что характерно для воскресных и будничных понев. Орнаменты подшивки символизируют магическое заклинание, обращенное к земле, поскольку используют ромбы (глазки), а также вертикальный зигзаг, имитирующий движение дождевой воды (цветной столбик).

Обязательными элементами воронежского комплекса являются широкий тканый пояс, головной убор «сорока» и нагрудное украшение «грибатка». Сорока богато декорировалась вышивкой в техниках золотного шитья, но в Алтайском крае этнографических образцов, которые можно было бы изучить и описать, к сожалению, не сохранилось.

Поневный комплекс, привезенный из родных мест, как уже указывалось выше, не получил распространения в Алтайском крае. Очень скоро воронежские 
переселенцы под веянием моды сменили его на юбку с кофтой, так называемую парочку. Впереди кофта богато декорировалась вышивкой, но теперь это были уже совсем другие орнаменты. В основном это красно-черные или полихромные узоры, выполненные хлопчатобумажными нитями на льняном или хлопчатобумажном полотне с фитоморфными мотивами в технике простой крест. Подобными орнаментами вышивались и передники, они располагались гирляндой из растительных мотивов по подолу.

Образцами для большинства таких вышивок служили рисунки из специально изданных альбомов и оберток мыла парфюмерной фабрики Брокара и Ралле. Исследовательница Е.Э. Бломквист, посетившая Алтай в 20-е гг. XX в., отмечала, что эти городские узоры особенно быстрыми темпами заимствовались в послереволюционные годы, когда край столкнулся с большим количеством «рассейских» переселенцев (Бломквист, 1930: 62).

Этнографические образцы «воронежских парочек» сохранились в Петропавловском районе, главным образом, в с. Соловьиха. По свидетельствам информантов, их носили вплоть до 60-х гг. ХХ столетия.

Таким образом, вышивка воронежских переселенцев Алтайского края представлена в поневном комплексе, в котором использованы наиболее архаичные техники и орнаменты, и в комплексе «юбка с кофтой», в которой нашли отражение «брокаровские» узоры.

Традиционная вышивка воронежских переселенцев - важный пласт культурного наследия, изучение которого дает понимание о процессах, которые происходили в жизни «рассейских». Одежда и способы ее изготовления, декорирования отражают мировоззрение данной этнической группы в разные временные и территориальные рамки, ее качественно новый переход из одних социальных устоев в другие. Если вышивка, используемая в поневном комплексе, несла магическо-заклинательную функцию, то в парочке - главным образом, эстетическую. На Алтае в процессе аккультурации воронежские переселенцы полностью утратили традиции вышивания своей метрополии. Но то обилие вышивки, которую они использовали в «новой моде», и тот факт, что они продолжали носить одежду с вышивкой в послевоенное время, говорят о том, что вышивка долгое время «на новой земле» оставалась приоритетным видом рукоделия.

\section{БИБЛИОГРАФИЧЕСКИЙ СПИСОК}

Бломквист Е.Э. Искусство бухтарминских старообрядцев. В кн.: Бухтарминские старообрядцы. Л., 1930. С. 397-432.

Куприянова И.В. Вышивка «по набору»: технология реконструкции и методика расшифровки. Этнография Алтая и сопредельных территорий, 2005, No. 6. С. 239-244.

Липинская В.А. Старожилы и переселенцы. Русские на Алтае (XVIII — начало XX в.). М.: Наука, 1996. 269 с.

Сысоева Г.Я. Технологии традиционной черно-узорной вышивки в селах воронеж- 
ко-белгородского пограничья. Культура.РФ, 2017a. URL: https://www.okrae.odbvrn. ru/voronezhskii-narodnyi-kostyum (дата обращения 03.05.2019).

Сысоева Г.Я. Традиционные технологии изготовления понев в селах воронежско-белгородского пограничья. Культура.РФ, 2017б. URL: https://www.culture.ru/ objects/2976/tradicionnye-tekhnologii-izgotovleniya-ponev-v-selakh-voronezhskobelgorodskogo-pogranichya (дата обращения 03.05.2019).

\section{REFERENCES}

Blomkvist, E.Je. (1930). Iskusstvo buhtarminskih staroobrjadcev [The art of old believers from Bukhtarma]. In. Buhtarminskie staroobrjadcy . L., 397-432.

Kuprijanova, I.V. (2005). Vyshivka «po naboru»: tehnologija rekonstrukcii i metodika rasshifrovki [Embroidery «on the kit»: technology of reconstruction and method of decryption]. Jetnografija Altaja i sopredel'nyh territorij, no 6, 239-244.

Lipinskaja, V.A. (1996). Starozhily i pereselency. Russkie na Altae (XVIII - nachalo XX v. ) [Old-timers and settlers. Russians in the Altai from the XVIII to the beginning of the XX ceinturies]. M.: Nauka.

Sysoeva, G.Ja. 2017a. Tehnologii tradicionnoj cherno-uzornoj vyshivki v selah voronezhko-belgorodskogo pogranich'ja [Technologies of traditional black-patterned embroidery in the villages of Voronezh and Beldorod borderland]. Kul'tura.RF [Culture of Russia]. Available at: https://www.okrae.odbvrn.ru/voronezhskii-narodnyi-kostyum (accesed 03.05.2019).

Sysoeva, G.Ja. 2017b. Tradicionnye tehnologii izgotovlenija ponev v selah voronezhsko-belgorodskogo pogranich'ja [Traditional technologies of fabrication of skirts in the villages of Voronezh and Beldorod borderland]. Kul'tura. $R F$ [Culture of Russia]. Available at: https://www.culture.ru/objects/2976/tradicionnye-tekhnologii-izgotovleniya-ponev-v-selakh-voronezhsko-belgorodskogo-pogranichya (accesed 03.05.2019). 